\title{
Immunodiagnostics: The Convergence of Biotech and Public Health
}

\section{Aramís Sánchez Gutiérrez MS and Conner Gorry MA}

Conceiving, building, maintaining and refining a universal health system is an inordinately complex undertaking. Its effective implementation requires everything from political will consistently and strategically applied, to accurate epidemiological data and analysis, plus quality medical education and active citizen participation. It also takes resources - financial, technological, pharmaceutical and professional-a perennial challenge for a small, economically-constrained island nation like Cuba. Indeed, even some highly developed nations like the United States have yet to achieve universal health coverage. these technologies would need to be accessible to and appropriate for resource-scarce contexts; effective and efficient; with coverage of as many people as possible. The goal was to apply these technologies in active screening programs for early diagnosis of infectious and chronic non-communicable diseases, as well as to congenital conditions that have a high medical and social impact or are major causes of morbidity or mortality in Cuba and thus targets for early intervention at the primary care level.[6] These include breast, colon and prostate cancers; Hepatitis B and C; HIV; dengue and diabetes.
In Cuba's case, resource scarcity itself, coupled with the need to develop a sustainable health care model sufficiently independent of global geopolitical and economic turbulence, has, paradoxically, led to the establishment of a key health system component: a robust domestic biopharmaceutical industry.[1] A Global South leader in biotech R\&D, Cuba produces innovative vaccines and therapies-many unique in the world-such as Heberprot-P, Nimotuzumab, VA-MENGOC-BC, and a synthetic antigen vaccine against Haemophilus influenzae b (Hib). [2] While these products are the headline-makers, diagnostic systems and equipment designed, built and distributed by Havana's Immunoassay Center (CIE, the Spanish acronym) have quietly but consistently contributed to improving Cuban and global health for over two decades.

\section{Background}

Cuba's aggressive push to develop a domestic biotech sector dates to the early 1980 s when a cluster of scientific research and manufacturing institutions were established to produce interferon, recombinant proteins and other biotech products. These institutions became the building blocks of Cuba's Scientific Pole, a scientific campus located in western Havana, which today comprises 24 research institutions and 58 manufacturing facilities, employs more than 7000 scientists and engineers[3] and collectively accounted for US\$711 million in export earnings in 2011; this makes it the country's largest revenue-earning manufacturing industry after nickel.[4]

Founded in 1987, CIE was one of the Scientific Pole's seminal institutions. CIE researchers challenged themselves to "look for technologies of the future, to see what we could do that could be applied throughout a national public health system," Director José Luis Fernández Yero told MEDICC Review.[5] By design,
Developing medical technologies for population health is only one piece of the puzzle, however. To be effective, such technologies must be applied rationally and through a coordinated strategy that includes laboratory networks to process diagnostic tests, trained professionals to interpret results, and maintenance programs to keep equipment functioning. By working closely with Cuba's Ministry of Public Health (MINSAP, the Spanish acronym) and the national programs applying the technologies, CIE products provide nationwide coverage for detection, surveillance and monitoring of the chief causes of death and years of productive life lost in Cuba.

\section{Applying Technology to Improve Population Health}

Several CIE technologies pre-date its founding. In 1981, Cuba began a pilot program using an ultramicroanalytic system (SUMA) to detect congenital malformations and in 1986 began providing screening for congenital hyperthyroidism in newborns - the second country in the hemisphere to do so, after Canada.[5] Today, CIE has a robust portfolio of 33 diagnostic tests used in the national health system for the detection, monitoring and evaluation of 19 diseases; they are regarded as the first link in a chain of complementary and confirmatory diagnostics.

These tests are used in active screening programs to identify risk factors in the population and permit early diagnosis in people who have, or are at greater risk for, a particular disease, even before the onset of symptoms. This increases therapeutic options, decreases complications and mortality, and improves quality of life. Early detection also lowers overall costs to the health system, since fewer patients will progress towards advanced stages of disease.

CIE also designs, develops and manufactures equipment and instruments used in diagnostic testing and the software need- 
Cuban Immunoassay Technology in the National Public Health System

\begin{tabular}{|c|c|c|c|c|}
\hline Test & Technology & $\begin{array}{c}\text { Year } \\
\text { Introduced }\end{array}$ & $\begin{array}{c}\text { Number of Tests Performed } \\
\text { and/or Universe } \\
\text { (through July } 31,2012 \text { ) }\end{array}$ & Cases Detected \\
\hline \multicolumn{5}{|l|}{ PREGNANT WOMEN } \\
\hline Birth defects (alpha-fetoprotein) & UMELISAAFP & 1982 & $3,755,511$ & 8011 \\
\hline $\begin{array}{l}\text { Ectopic pregnancy and trophoblastic } \\
\text { disease (human chronic gonadotropin) }\end{array}$ & UMELISA HCG & 1992 & $\begin{array}{l}\text { Case-by-case basis (available } \\
\text { nationwide) }\end{array}$ & $\mathrm{n} / \mathrm{a}$ \\
\hline \multicolumn{5}{|l|}{ NEWBORNS } \\
\hline $\begin{array}{l}\text { Congenital hypothyroidism (thyroid stimu- } \\
\text { lating hormone) }\end{array}$ & UMELISA NEONATAL TSH & 1986 & $3,350,373$ & 801 \\
\hline Phenylketonuria (Phe) & UMTEST PKU & 2000 & $1,055,575$ & 20 \\
\hline $\begin{array}{l}\text { Congenital adrenal hyperplasia }(17-\mathrm{OH}- \\
\text { progesterone) }\end{array}$ & $\begin{array}{l}\text { UMELISA } 17 \text { OH NEONATAL } \\
\text { PROGESTERONE }\end{array}$ & 2005 & 780,771 & 45 \\
\hline Biotinidase deficiency (biotinidase) & UMTEST BIOTINIDASE & 2005 & 759,935 & 5 \\
\hline Galactosemia (galactose) & UMTEST GAL & 2005 & 723,182 & 7 \\
\hline \multicolumn{5}{|l|}{ INFECTIOUS DISEASES } \\
\hline HIVIAIDS (anti-HIV 1 \& 2 lgG antibodies) & $\begin{array}{l}\text { UMELISA HIV } 1 \& 2 \text { RECOMBI- } \\
\text { NANT }\end{array}$ & 1988 & $\begin{array}{l}47,411,375 \\
\text { (includes blood donors, } \\
\text { pregnant women and general } \\
\text { epidemiological surveillance) }\end{array}$ & $\begin{array}{l}\text { 15,284 seropositive } \\
\text { tests } \\
\text { Blood donors: } 0.64 \%\end{array}$ \\
\hline \multirow{5}{*}{$\begin{array}{l}\text { Hepatitis B (HBsAg \& other serological } \\
\text { markers) }\end{array}$} & UMELISA HBsAg PLUS & \multirow{5}{*}{1986} & \multirow{5}{*}{$\begin{array}{l}20,270,560 \\
\text { (Includes blood donors, } \\
\text { pregnant women and general } \\
\text { epidemiological surveillance) }\end{array}$} & \multirow{5}{*}{$\begin{array}{l}\text { Confirmed cases in } \\
\text { blood donors: } 77,508 \\
\text { ( } 0.89 \% \text { of blood } \\
\text { donors) }\end{array}$} \\
\hline & HBsAg CONFIRMATORY TEST & & & \\
\hline & UMELISAANTI- HBsAg & & & \\
\hline & UMELISA ANTI-HBC & & & \\
\hline & UMELISA ANTI-HBc IgM & & & \\
\hline \multirow[t]{2}{*}{ Hepatitis C (anti-HCV) } & UMELISA HCV & 1992 & $\begin{array}{l}10,615,685 \\
\text { (Includes blood donors, } \\
\text { pregnant women and general } \\
\text { epidemiological surveillance) }\end{array}$ & $\begin{array}{l}\text { Reactivity in blood } \\
\text { donors: } 0.90 \%\end{array}$ \\
\hline & UMELOSA HCV (PCR) & 2005 & 6531 & 3282 \\
\hline Dengue (IgM antibodies) & UMELISA DENGUE IgM PLUS & 1995 & 530,677 & $\mathrm{n} / \mathrm{a}$ \\
\hline Leprosy (IgM antibodies) & UMELISA HANSEN & 1993 & 25,354 & Reactivity: $8.1 \%$ \\
\hline Chagas (IgG antibodies) & UMELISA CHAGAS & 1994 & 12,260 & Reactivity: $4.9 \%$ \\
\hline Tetanus (IgG antibodies) & UMELISA TETANUS & 1996 & 47,070 & $\begin{array}{l}\text { Donors with required } \\
\text { titers used for produc- } \\
\text { tion of human tetanus } \\
\text { immunoglobulin: } \\
23,208\end{array}$ \\
\hline \multicolumn{5}{|c|}{ CHRONIC NON-COMMUNICABLE CONDITIONS } \\
\hline Diabetes mellitus (blood glucose) & $\begin{array}{l}\text { SUMAsensor (glucometer and } \\
\text { biosensors) }\end{array}$ & 2008 & 513,405 & $\begin{array}{l}\text { 130,316 glucometers } \\
\text { and } 26 \text { million } \\
\text { dipsticks: } 85 \% \text { for } \\
\text { patients registered and } \\
\text { treated in primary care }\end{array}$ \\
\hline $\begin{array}{l}\text { Prostate cancer (prostate-specific } \\
\text { antigen) }\end{array}$ & UMELISA PSA & 2003 & 464,683 & $\mathrm{n} / \mathrm{a}$ \\
\hline Microalbuminuria (microalbumin) & UMELISA MICROALBUMINA & 2010 & 351 & 109 \\
\hline Colon cancer (fecal occult blood) & SUMASOHF & 2012 & 7450 & $\begin{array}{l}14 \\
\text { Other diseases: } 541\end{array}$ \\
\hline Atopic diseases (Total lgE) & UMELISA IgE & 1987 & $\begin{array}{l}\text { Children with suspected } \\
\text { allergies }\end{array}$ & $\mathrm{n} / \mathrm{a}$ \\
\hline
\end{tabular}


ed to process results. These include fluorometers/photometers, slide washers, punches for samples collected on filter paper, multichannel pipettes for dispensing reagents and specimens, and the VS-850 spectrophotometer, widely used in clinical biochemistry tests. Two of CIE's newest technologies are the SUMASCOPE video colposcope, used to examine the vaginal interior to assess topography, coloration, configuration, vascular architecture and degree of cervical alteration; and the Estereoflex stereotaxic frame for minimal access neurosurgery. The latter enables surgeons to reach superficial or deep brain structures with extreme precision and thus perform open computer-assisted, image-guided stereotaxic neurosurgical procedures.[6]

The main programs utilizing SUMA technology in Cuba's public health system include:

- Maternal and child health

- Blood certification

- Epidemiological surveillance

- Placenta certification

- Organ certification

- Prostate, cervical, colon and breast cancer

- Adult metabolic disorders

- Minimal access neurosurgery

These programs and others using the technologies are linked to a network of 234 diagnostic laboratories across the island. Additionally, there are 168 Comprehensive Active Screening Centers (CEPAI, the Spanish acronym)-one in each municipalityembedded in the majority of these laboratories. Both the laboratories and CEPAls are staffed by technicians trained and certified by $\mathrm{CIE}$, which pairs new personnel with experienced technicians upon completion of a certification course. The laboratories are supported by five regional CIE technical support centers that repair equipment and ensure supplies of equipment, instruments and reagents.

This national network of laboratories and support centers significantly impact quality of patient care. Previously, diagnostic testing was limited to the provincial capitals, meaning patients in outlying and remote municipalities had to wait for results to return to their primary care facility. Locating testing at municipality-based CEPAls results in a more efficient process, improved diagnostic quality and less stress for patients who get their test results more quickly. A procedural change is also

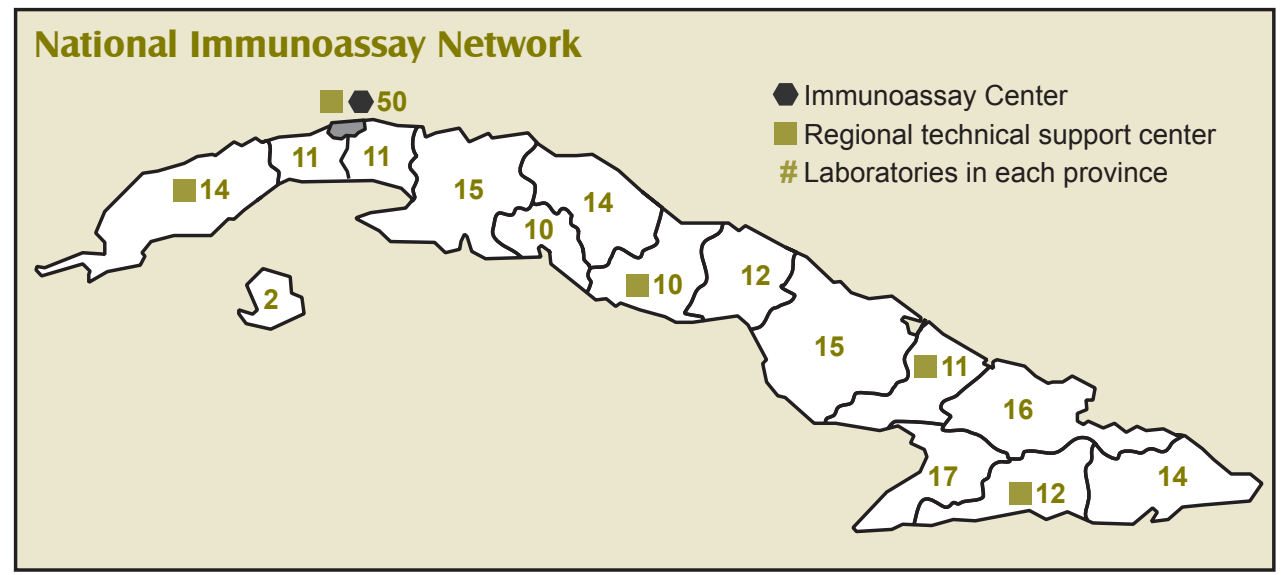

Source: CIE, Havana 2012 improving care: whereas before patients were only notified if they tested positive for a disease or condition, now they receive notification regardless of the result. Decentralization of equipment maintenance is likewise impacting care, since it means faster service for broken equipment.

In Cuba, chronic non-communicable diseases account for some $60 \%$ of deaths a year, providing impetus to develop strategies and technologies for their diagnosis and monitoring. With this in mind, CIE introduced the SUMAsensor in 2008, a glucometer designed specifically for tropical climates (dipsticks individually packaged in aluminum blisters). Results appear in 25 seconds and the unit stores up to 220 results, displaying the date and time they were registered. Thus far, over 130,000 SUMAsensors and 26 million dipsticks have been distributed, $85 \%$ of them to insulin-dependent diabetics and the rest to health facilities. About $80 \%$ of insulin-dependent diabetics have received the glucometer, but the goal is to step up distribution to provide total coverage. In 2013, distribution to pregnant women with diabetes and people with type 2 diabetes will commence. Carmen Ramírez, an 84-year old diabetic from Regla, Havana, uses the SUMAsensor daily to measure her blood sugar levels. "It's so simple to use and I like being able to monitor my blood sugar from home. When there are fluctuations, I go to my doctor and she knows exactly what my levels have been by looking at my glucometer," she told MEDICC Review.[7]

\section{In Search of Sustainability}

Technological and diagnostic applications are particularly costly and often put health systems at the mercy of companies driven mainly by commercial considerations. Cuba's universal health system has adopted a social justice approach committed to care for all, addressing neglected diseases, and prioritizing vulnerable populations (which have little influence in an industry focused on the bottom line). Maintaining a universal health system and improving population health in a resource-scarce setting such as Cuba-where additional restrictions are imposed by the US embargo[8]_-is a constant struggle.

Thus, CIE was founded, a domestic R\&D center designed to ensure stable, sustainable product availability and relative independence from global volatility. The Center substitutes imports, and also exports its technology to finance research, development, manufacturing and distribution. Import substitution is fundamental to the formula's success, not only for the savings it provides the health system, but for the independence it represents for the sector. While all raw materials for CIE products must be purchased on the international market, $100 \%$ of the Center's technologies and instruments are manufactured domestically, representing an important degree of 'technology sovereignty' and sustainability. For example, import substitution of reagents used in CIE's diagnostic kits has saved the public health system US\$300 million to date.

CIE sales abroad support this quest for sustainability: currently there are 469 laboratories using CIE products in 
some half a dozen countries, including Brazil, Argentina, China and Mexico.[9] The Cuban approach-locating laboratories near patients, CIE certification courses for technicians, strategicallyplaced servicing and maintenance branches-is adapted to each site. The most popular products internationally are the SUMAsensor, reagents and an innovative cytology kit-one of CIE's newest products-developed jointly with the National Cancer Control Unit and the Cervical Cancer Early Diagnosis Program. International demand for $\mathrm{CIE}$ technologies and instruments (all of which undergo external evaluations and adhere to international quality control and certification standards) is growing - so much so that CIE is currently working at double capacity and is expanding its physical plant to keep pace.

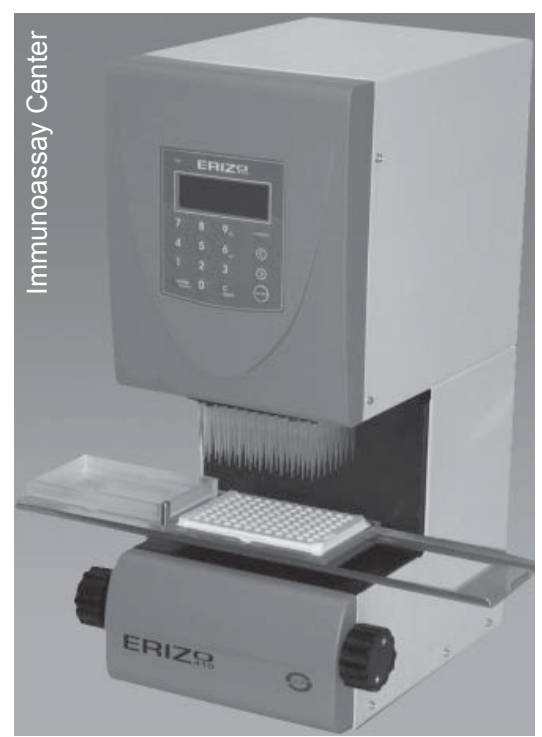

Multichannel pipettes dispensing reagents and specimens manufactured in Cuba help provide sustainability to the health system.
Sales of CIE products have rendered the institution financially independent of all public funding, which the Center has not received since the 1990s, according to Director Fernández Yero.[5] Such solvency translates into savings for the national public health system as well, since it allows CIE to keep production costs and prices low. The SUMASCOPE is one example: this digital video colposcope costs US $\$ 10,000$ on the international market, but CIE sells it to the Cuban public health system for US\$300. It should be mentioned that low salaries for scientists, researchers and other professionals-an issue government has consistently promised to address as Cuba continues its program of economic reforms initiated in 2011-is another factor reducing production costs.

\section{Conclusion}

The Cuban biopharmaceutical industry is a patient-first model characterized by prioritizing vulnerable populations; providing quality products at accessible prices and locations; and tailoring research and development to the health picture of the country. CIE and other institutions in the Scientific Pole pursue this strategy consistently and comprehensively in coordination with MINSAP and its national programs. While patient-based, the sector is increasingly looking for ways to become more efficient to increase savings, and to more actively increase export revenuesboth critically important in today's uncertain global economy.

Knowing which technologies are needed to address pressing health needs-such as the burden of chronic non-communicable diseases facing the country-requires cooperation and input from primary care providers, specialists and epidemiologists. Having a unified, universal system facilitates this cooperation.

Meanwhile, designing, manufacturing and distributing such technologies in an appropriate way for the context in which they will be used (concepts embedded in CIE's mission) has shown results in Cuba and elsewhere. One lesson emerging from Cuba's experience with immunodiagnostic technologies is that, once testing is completed, they are only as useful as the attention patients receive in primary care and related health services. In short, such technologies must be supported by quality treatment and monitored followup to positively affect both individual and population health - the role and goal of the health system itself. - 1 -

\section{References \& Notes}

1. For more see Gorry C. Biotech: The magic pill? in Scientific American worldVIEW. March 2012.

2. To read more about these Cuban biotech products see MEDICC Rev. 2007 Fall;9(1); MEDICC Rev. 2009 Summer;11(3); MEDICC Rev. 2010 Winter;12(1); and Berlanga et al. in this issue of MEDICC Review.

3. Lage A. Global pharmaceutical development and access: Critical issues of ethics and equity. MEDICC Rev. 2011 July:13(3):16-22.

4. Scheye E. Cuban healthcare and biotechnology: Reform, a bitter pill to swallow or just what the doctor ordered? Paper presented at: Cuba in Transition: Volume 21. Proceedings of the Twenty-first Annual Meeting of the Association for the Study of Cuban Economy (ASCE); 2011 Aug 4-6; Miami, Fla.

5. Reed G. Generating appropriate technologies for health equity: José Luis Fernández Yero. MEDICC Rev. 2009 Winter:11(1):14-7.

6. Sánchez Gutiérrez A. Immunoassay Center: 25 years improving public health. Forthcoming.

7. Interview with: Gorry C. 2012 Nov 29.

8. For specifics about the US embargo effects on Cuban health, see Amnesty International. The US Embargo against Cuba: Its Impact on Social and Economic Rights. September 2009.

9. Immunoassay Center (CU). Sistema Ultra Micro Analítico: Una nueva dimensión en el inmunodiagnóstico. Havana: TecnoSuma Internacional, SA; 2012. www.tecnosuma.com. Spanish. 